\title{
ANÁLISE MULTITEMPORAL COM MAPEAMENTO EM UMA APP NO RIO PIRANHAS, MUNICÍPIO DE JARDIM DE PIRANHAS-RN
}

\author{
Carlos Roberto da Silva Filho ${ }^{(a)}$, Denise Santos Saldanha ${ }^{(b)}$, Jânio Carlos Fernandes Guedes ${ }^{(c)}$, \\ Diógenes Félix da Silva Costa ${ }^{(d)}$
}

(a) Grupo de Pesquisa em Geoecologia e Biogeografia de Ambientes Tropicais - TRÓPIKOS /UFRN, carloslamma@gmail.com

(b) Grupo de Pesquisa em Geoecologia e Biogeografia de Ambientes Tropicais - TRÓPIKOS /UFRN, denisesaldanha.lama@gmail.com

(c) Grupo de Pesquisa em Geoecologia e Biogeografia de Ambientes Tropicais - TRÓPIKOS /UFRN, janiocf.guedes@gmail.com

(d) Líder do TRÓPIKOS/UFRN, diogenes.costa@pq.cnpq.br

\section{Eixo: GEOTECNOLOGIAS E MODELAGEM ESPACIAL EM GEOGRAFIA FÍSICA}

\begin{abstract}
Resumo
O planejamento ambiental requer estudos integrados nos quais sistematizem informações sobre a área em que será aplicado e identifique o estado do ambiente. Nessa perspectiva, o presente trabalho pretende-se utilizar da Ecologia da Paisagem para delimitação e monitoramento multitemporal da Área de Preservação Permanente - APP em um trecho de rio no semiárido mediante ao novo código florestal. Utilizaram-se imagens dos satélites CBERS 2B e do Geoeye nos softwares ArcGIS 10.2 e o Envi 4.7, empregando-se ferramenta Buffer para delimitação. A calha regular variou entre $28 \mathrm{~m}$ e $68 \mathrm{~m}$ em 2009, sendo que, a APP deve ter 100m de largura. Considerando os parâmetros climáticos da área, a calha regular variou entre 18 e 43 metros em 2012. Considerando a média de 33m da calha em 2012, constata-se, segundo a legislação vigente, a validez da delimitação da APP de 50m. Portanto, a Ecologia da Paisagem mostrou-se eficaz na delimitação e monitoramento das APPs.
\end{abstract}

Palavras chaves: Ecologia da paisagem, SIG, planejamento ambiental.

\section{Introdução}

Estudos relacionados ao desenvolvimento sustentável são um dos desafios da sociedade atual, que junto com a ciência, vem fornecendo suporte instrumental para a caracterização multitemporal de padrões ambientais, como por exemplo, uso e cobertura do solo, visando melhorar ou sugerir propostas de planejamento para o uso desses locais, assim como para delimitar áreas prioritárias para conservação da biodiversidade existente (FARIA et al., 2012).

Segundo definição do código florestal brasileiro (art. $1^{\circ}$, § II, inciso II da Lei 4.771/65) áreas de preservação permanente são áreas que coberta por vegetação, que tem a função ambiental de preservar os recursos hídricos, a paisagem, a estabilidade geológica, a biodiversidade, o fluxo gênico de fauna e flora, proteger o solo e assegurar o bem-estar das populações humanas (BRASIL, 2013). 
A Ecologia da Paisagem tem se mostrado como uma das ciências mais eficazes na análise e planejamento da paisagem em geral (KLINK, 1981), já que os índices de paisagem, enquanto descritores espaciais oferecem uma valiosa visão das similaridades e diferenças de estrutura e função entre mosaicos de cobertura vegetal em diferentes paisagens.

As APP surgiram a partir do conhecimento sobre a importância da manutenção da vegetação para a preservação da qualidade da água e do solo, bem como comodidade à população, sendo essas áreas protegidas pela legislação desde a década de 60 (SANTOS, 2012).

Dentro da visão de proteção ambiental, os Sistemas de Informações Geográficas (SIG) são criados para servirem de bases para as tomadas de decisão, assim, para obter informações e utilizá-las com fins de gerar respostas que satisfaçam às necessidades do planejamento ambiental, fazendo-se necessária à existência de uma base cartográfica e um sistema de informações estruturado (NICÁCIO, 2002).

Nessa perspectiva, o presente trabalho pretende utilizar da Ecologia da Paisagem para delimitação e monitoramento multitemporal da APP em um trecho do Rio Piranhas-Açu, localizado na cidade de Jardim de Piranhas-RN, mediante ao novo código florestal.

\section{Metodologia}

O Rio Piranhas está inserido dentro da Bacia Hidrográfica Piranhas-Açu, localizada entre os estados da Paraíba e Rio Grande do Norte, mais precisamente entre os pares de coordenadas: 450'16,93" e $7^{\circ}$ 00'42,94" de latitude Sul, e 3606'18,01" e 3741'46,76” de longitude Oeste, no Semiárido Nordestino (AMORIM et al, 2007). A área em análise engloba um trecho do Rio Piranhas-Açu, que fica localizado na cidade de Jardim de Piranhas/RN, próximo ao CAP "Clube Atlético Piranhas". 


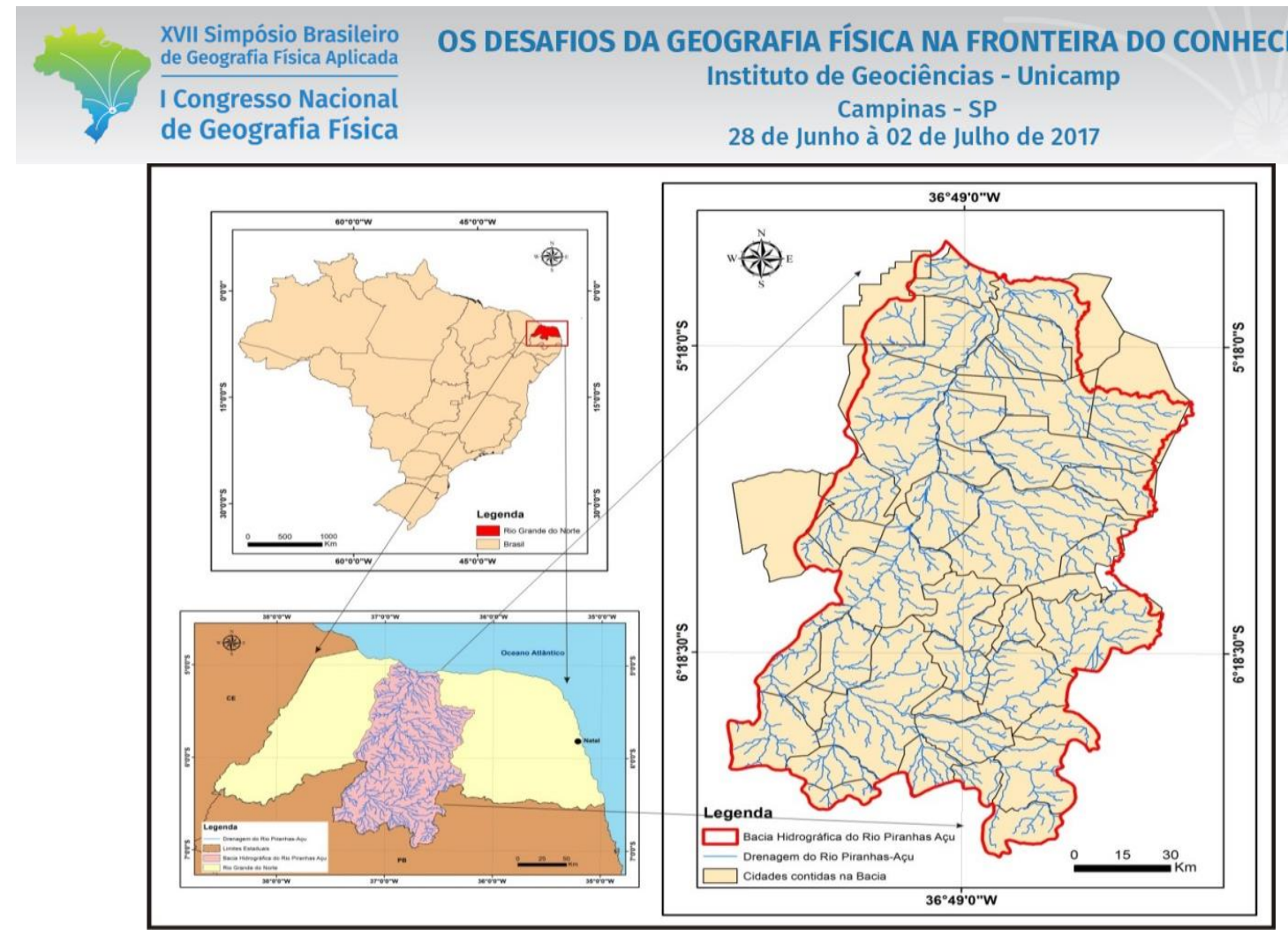

Figura 1 - Mapa de localização das cidades contidas na Bacia do Rio Piranhas-Açu no Estado do Rio Grande do Norte.

Realizou-se avaliação de campo com a utilização de um GPS Garmin a fim de se coletar pontos de controle na área em análise para uma melhor precisão frente ao georreferenciamento do local.

Todo o material cartográfico foi elaborado a partir de imagens do satélite CBERS 2B (sensor: HRC órbita 149-E, ponto 107-4, monocromática e resolução espacial de 2,7 metros, obtida em 21/07/2009). Essas imagens são disponibilizadas gratuitamente pelo Instituto Nacional de Pesquisas Espaciais (INPE), as quais passaram por um processo de fusão de bandas no software Arcgis 10 (versão acadêmica - ESRI ${ }^{\odot}$ ), a partir do qual foi obtida uma imagem resultante em falsa cor (Red-Green-Blue) com resolução espacial de 2,7 metros. Como também imagens do satélite Geoeye datando 31 de agosto de 2012, obitidas pelo WebSIG Google Earth $\left(\right.$ Google $\left.^{\mathcal{O}}\right)$.

No software Envi 4.7 foram realizados o realce de contraste das imagens de satélite, mapeamento e produção do material cartográfico. As cenas foram mosaicadas em ambiente de Sistema de Informação Geográfica (SIG).

Após o catálogo das imagens de satélites de períodos distintos, foi plotado um Buffer a partir da calha regular do leito maior, onde conforme a Lei 12.651/2012 estabelece padrões diferentes de medição das APPs. 
XVII Simpósio Brasileiro

de Geografia Física Aplicada

I Congresso Nacional

de Geografia Física

\section{OS DESAFIOS DA GEOGRAFIA FÍSICA NA FRONTEIRA DO CONHECIMENTO \\ Instituto de Geociências - Unicamp \\ Campinas - SP \\ 28 de Junho à 02 de Julho de 2017}

Para a tabulação e armazenamento dos dados foi utilizado o software Microsoft Office Excel (Microsoft ${ }^{\circ}$ )

Todas as etapas de gabinete (seleção, georreferenciamento e classificação/processamento das imagens) foram realizadas com apoio logístico e operacional do Laboratório de Monitoramento Ambiental - LAMA (UFRN/CERES - Campus de Caicó).

\section{Resultados e Discussão}

Na Figura 2 (imagem de satélite de 2009), percebe-se que no trecho analisado, a calha regular variou entre 28 e 68 metros, onde conforme o novo código florestal, a mesma deve apresentar uma APP com uma largura de 100 metros. Como ponto de referência, conforme já especificado, adotamos o CAP (Clube Atlético Piranhas).

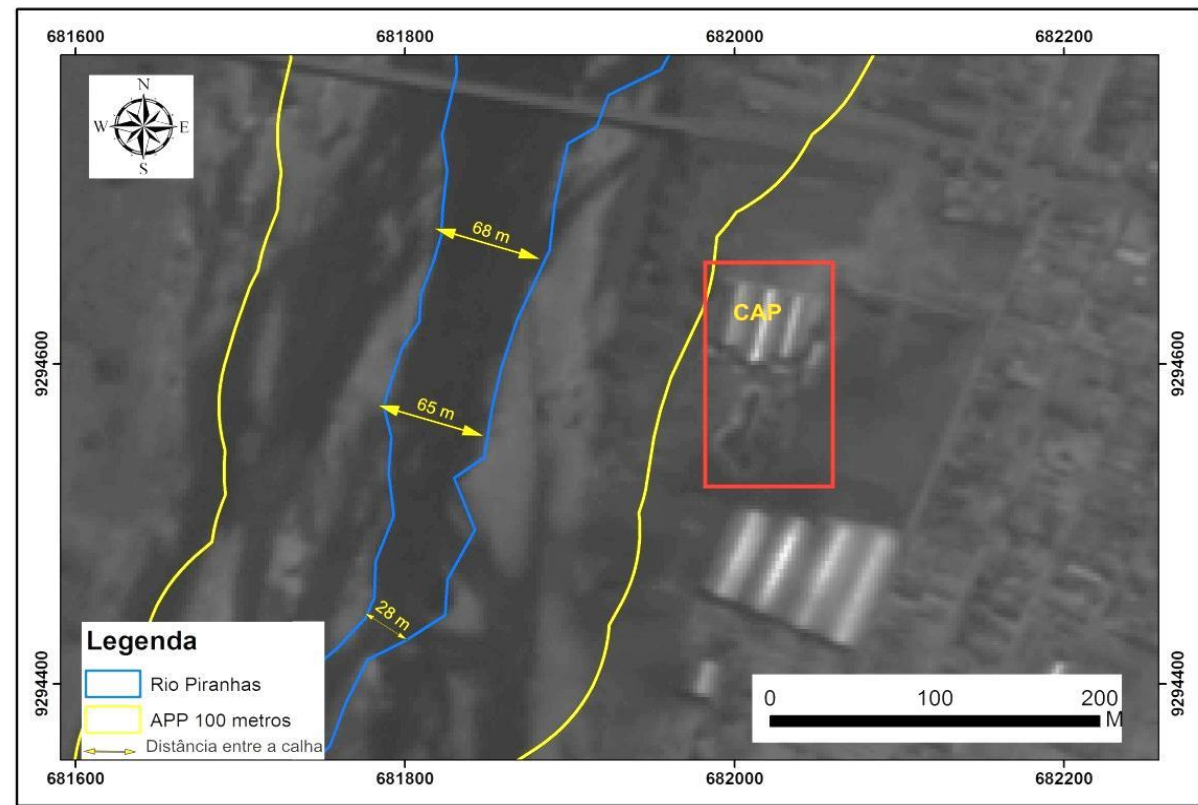

Figura 2 - Mapa de delimitação da APP de 100 metros no trecho do Rio Piranhas (2009).

Através do mapa elaborado a partir da imagem do Satélite CBERS 2B, percebe-se que conforme os parâmetros estabelecidos pelo o novo Código Florestal de 2012, levando em consideração a localização do perímetro urbano como ponto de referência, verificou-se na imagem de 2009 um fluxo de água intermediário, com a inundação em um nível acima da calha principal do rio, porém abaixo do leito maior. Considerando-se a imagem de 2009 (Inundação sazonal abaixo do leito regular), identificou-se uma distância média de 53 metros entre as bordas da calha principal nas imediações do perímetro urbano. Esse 
cenário enquadra-se claramente no descrito na alínea "c", que delimita a APP de 100 metros para os cursos d'água que tenham de 50 (cinquenta) a 200 (duzentos) metros de largura.

Avaliando-se a delimitação da APP na imagem do ano de 2012 (fluxo de água apenas na calha do leito regular), onde se deve, de fato, efetuar a delimitação da APP segundo a legislação vigente, identificou-se uma distância média de 33 metros entre as bordas do leito regular, nas imediações do CAP.

Portanto, a delimitação da APP neste trecho do Rio Piranhas-Açu enquadra-se no descrito na alínea "b", que delimita a APP de 50 (cinquenta) metros para os cursos d'água que tenham de 10 (dez) a 50 (cinquenta) metros de largura.

Nesse caso, percebe-se a partir da interpretação da imagem, que o CAP não se encontra inserido dentro da APP.

\section{Conclusão}

Verificou-se que a Ecologia da Paisagem, mesmo por se mostrar como uma ciência voltada ao planejamento ambiental de caráter mais conservacionista a mesma mostrou-se eficaz na delimitação e monitoramento das APPs, onde se utilizou das imagens de satélites para uma análise multitemporal da Área de Proteção Permanente em um trecho do Rio Piranhas, conforme os parâmetros estabelecidos pelo o novo código florestal (Lei 12651/2012).

\section{Bibliografia}

BERTRAND, G. Paisagem e Geografia Física global: esboço metodológico. Caderno de Ciências da Terra, v. 13, n. 8, p. 1-21. São Paulo, 1969.

BRASIL. LEI $\mathbf{N}^{\mathbf{0}}$ 4.771, de 15 de Setembro de 1965 . Disponível em: http://www.ambiente.sp.gov.br/madeiralegal/CodigoFlorestal.pdf>. Acesso em: 16 de Novembro de 2013.

Resolução Conama Lei $\mathbf{N}^{\circ} 12651$ de Maio de 2012. Disponível em: <http://www.planalto.gov.br/ccivil_03/_Ato2011-2014/2012/Lei/L12651.htm>. Acesso em: 16 de novembro de 2013.

FEREZ, J. M. Adequação ambiental: emprego de ferramentas de geoprocessamento em sistema de informações geográfica (SIG) para a conservação. Monografia (Especialização em Gerenciamento Ambiental), Escola Superior de Agricultura Luis Queiroz, Universidade de São Paulo, Piracicaba/SP. 2011. 58 f.

KLINK, H.J. Geoecologia e regionalização natural: bases para Pesquisa Ambiental. Biogeografia 17, São Paulo: Instituto de Geografia - USP, 1981. 


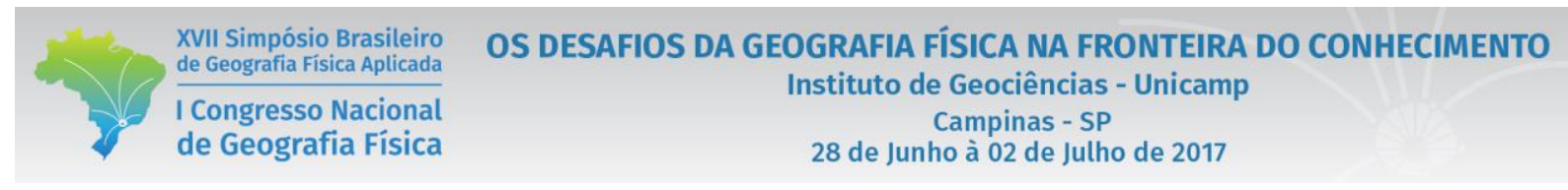

NICÁCIO, J. Â. Elementos necessários para o planejamento da sustentabilidade dos municípios de médio e pequeno porte. Dissertação (Mestrado em Engenharia de Produção). Programa de Pós-graduação em Engenharia de Produção. Florianópolis: UFSC, 2002.

SANTOS, N. C.; Avaliação dos usos e ocupações do solo na APP do Rio Araguaia e sua compatibilidade legal no perímetro urbano de Conceição do Araguaia - PA. Anais III Congresso Brasileiro de Gestão Ambiental Goiânia/GO -2012 .

FARIA, K. M. S; SIQUEIRA, M. N; CARNEIRO, G. T; CASTRO, S. S. Análise Geoecológica da Conservação Ambiental das Sub-Baciasdo Rio Claro (GO) e do Rio Garças (MT). Revista Nordestina de Ecoturismo, v. 5, n. 1, p. 1-11, 2012. 